International Journal of Environmental Research and

Public Health

ISSN 1660-4601

www.mdpi.com/journal/ijerph

Review

\title{
Review of Pesticide Urinary Biomarker Measurements from Selected US EPA Children's Observational Exposure Studies
}

Peter P. Egeghy ${ }^{1}{ }^{*}$, Elaine A. Cohen Hubal ${ }^{2}$, Nicolle S. Tulve ${ }^{1}$, Lisa J. Melnyk ${ }^{3}$, Marsha K. Morgan ${ }^{1}$, Roy C. Fortmann ${ }^{1}$ and Linda S. Sheldon ${ }^{1}$

1 Human Exposure and Atmospheric Sciences Division, National Exposure Research Laboratory, Office of Research and Development, U.S. Environmental Protection Agency, Research Triangle Park, NC 27711, USA; E-Mails: tulve.nicolle@epa.gov (N.S.T.); morgan.marsha@epa.gov (M.K.M.); fortmann.roy@epa.gov (R.C.F.); sheldon.linda@epa.gov (L.S.S.)

2 National Center for Computational Toxicology, Office of Research and Development, U.S. Environmental Protection Agency, Research Triangle Park, NC 27711, USA;

E-Mail: hubal.elaine@epa.gov

3 Microbiological and Chemical Exposure Assessment Research Division, National Exposure Research Laboratory, Office of Research and Development, U.S. Environmental Protection Agency, Cincinnati, OH 45268, USA; E-Mail: melnyk.lisa@epa.gov

* Author to whom correspondence should be addressed; E-Mail: egeghy.peter@epa.gov; Tel.: +1-919-541-4103; Fax: +1-919-541-0905.

Received: 2 March 2011; in revised form: 12 May 2011 / Accepted: 17 May 2011 /

Published: 24 May 2011

Abstract: Children are exposed to a wide variety of pesticides originating from both outdoor and indoor sources. Several studies were conducted or funded by the EPA over the past decade to investigate children's exposure to organophosphate and pyrethroid pesticides and the factors that impact their exposures. Urinary metabolite concentration measurements from these studies are consolidated here to identify trends, spatial and temporal patterns, and areas where further research is required. Namely, concentrations of the metabolites of chlorpyrifos (3,5,6-trichloro-2-pyridinol or TCPy), diazinon (2-isopropyl-6-methyl-4-pyrimidinol or IMP), and permethrin (3-phenoxybenzoic acid or 3-PBA) are presented. Information on the kinetic parameters describing absorption and elimination in humans is also presented to aid in interpretation. Metabolite concentrations varied more dramatically across studies for 3-PBA and IMP than for TCPy, with TCPy concentrations about an order of magnitude higher than the 3-PBA concentrations. 
Temporal variability was high for all metabolites with urinary 3-PBA concentrations slightly more consistent over time than the TCPy concentrations. Urinary biomarker levels provided only limited evidence of applications. The observed relationships between urinary metabolite levels and estimates of pesticide intake may be affected by differences in the contribution of each exposure route to total intake, which may vary with exposure intensity and across individuals.

Keywords: pesticides; urinary biomarkers; human exposure; residue intake; exposure trends; exposure variability

\begin{tabular}{|c|c|}
\hline$\%$ Det & Percent of samples above detection limit \\
\hline $2,4-\mathrm{D}$ & 2,4-Dichlorophenoxyacetic acid \\
\hline 3-PBA & 3-Phenoxybenzoic acid \\
\hline 4F3PBA & 4-fluoro-3-phenoxybenzoic acid \\
\hline 4OH3PBA & 3-(4'-hydroxyphenoxy) benzoic acid \\
\hline ATSDR & Agency for Toxic Substances and Disease Registry \\
\hline CHAM-QEA & $\begin{array}{l}\text { Center for the Health Assessment of Mothers and Children of Salinas } \\
\text { Quantitative Exposure Assessment Study }\end{array}$ \\
\hline CPPAES & Children's Pesticide Post-Application Exposure Study \\
\hline СТЕPP & $\begin{array}{l}\text { Children's Total Exposure to Persistent Pesticides and Other Persistent Organic } \\
\text { Pollutants Study }\end{array}$ \\
\hline DAP & Dialkylphosphate \\
\hline DBCA & 2,2-dibromovinyl-2,2-dimethyl-cyclopropane-1-carboxylic acid \\
\hline DCCA & 2,2-dichlorovinyl-2,2-dimethyl- cyclopropane-1-carboxylic acid \\
\hline DIYC & Dietary Intake of Young Children Study \\
\hline EOHSI & Environmental and Occupational Health Sciences Institute Study \\
\hline EPA & U.S. Environmental Protection Agency \\
\hline FMV & First morning void \\
\hline GM & Geometric mean \\
\hline GSD & Standard deviation of the geometric mean \\
\hline ICC & Intraclass Correlation Coefficient \\
\hline IMP & 2-Isopropyl-6-methyl-4-pyrimidinol \\
\hline JAX & $\begin{array}{l}\text { Biological and Environmental Monitoring for Organophosphate and Pyrethroid } \\
\text { Pesticide Exposures in Children Living in Jacksonville, Florida Study }\end{array}$ \\
\hline LOD & Limit of detection \\
\hline Max & Maximum \\
\hline MDA & Malathion dicarboxylic acid \\
\hline MDL & Minimum detection limit \\
\hline Min & Minimum \\
\hline MNCPES / MN & Minnesota Children's Pesticide Exposure Study \\
\hline MPA & 2-methyl-3-phenylbenzoic acid \\
\hline $\mathrm{N}$ & Sample size \\
\hline $\mathrm{NC}$ & North Carolina \\
\hline
\end{tabular}




$\begin{array}{ll}\text { NERL } & \text { National Exposure Research Laboratory } \\ \text { NHANES } & \text { National Health and Nutrition Examination Survey } \\ \text { NHEXAS-AZ } & \text { National Human Exposure Assessment Survey in Arizona } \\ \text { OH } & \text { Ohio } \\ \text { OP } & \text { Organophosphate } \\ \text { 25th } & \text { 25th percentile } \\ \text { 50th } & \text { Median/50th percentile } \\ \text { 75th } & \text { 75th percentile } \\ \text { 95th } & \text { 95th percentile } \\ \text { PBPK } & \text { Physiologically-Based Pharmacokinetic Model } \\ \text { PET } & \text { A Pilot Study Examining Translocation Pathways Following a Granular } \\ & \text { Application of Diazinon to Residential Lawns Study } \\ \text { SD } & \text { Standard deviation of the arithmetic mean } \\ \text { TCP } & \text { 3,5,6-Trichloro-2-pyridinol }\end{array}$

\section{Introduction}

There is currently a renewed emphasis within the U.S. Environmental Protection Agency (EPA) on protecting vulnerable subpopulations, especially children, and understanding children's exposure to chemicals [1]. Children are exposed to a wide variety of chemicals in their homes, schools, daycare centers, and other surroundings [2]. These chemicals may originate from outdoor sources such as ambient air contaminants or indoor sources such as building materials, furnishings, and consumer products. Among consumer products are pesticides used to control roaches, rats, termites, ants, and other vermin. Because of widespread residential and agricultural use, EPA has extensively studied children's exposures to pesticides over the past decade, particularly using biomarkers to assess the factors that impact exposure.

Biomarkers have the potential to play an important role in assessing aggregate exposure and informing cumulative risk assessment [3,4]. Biomarkers can be indicators of the body burden of a chemical, reflecting all routes of exposure, as well as inter-individual differences in absorption and metabolism. In human observational studies involving young children, urine is the primary vehicle for biomonitoring, being advantageous over blood in its noninvasiveness, ease of collection, and available quantities [5]. Compared to external concentrations of chemicals, biomarkers are often believed to be more directly related to potential adverse health effects [6,7]. Biomarkers, however, are not without their shortcomings, with disadvantages related to the cost and precision of the measurements, uncertainties in the fraction of the absorbed compound that is eliminated, and ambiguity in the overall relationship between biomarkers and external exposures [8,9]. Biomarkers in urine, in particular, are relatively short-lived and highly variable in concentration. Under these conditions it is often more difficult to relate biomarker concentrations to either health outcomes or exposures.

The relationship between a biological marker concentration and external exposure is influenced by factors related both to the environment and to human physiology as well as timing of the exposure and collection of the measurement. Factors related to the environment include spatial and temporal variability in exposure concentrations and effects of the presence of other chemicals [10]. Factors related to human physiology include differences in the rates of absorption, distribution, metabolism, 
and excretion, both over time and across individuals [11]. Biological monitoring performed concurrently with exposure monitoring may be used to investigate the influence of environment- and subject-specific factors on the relationship between the two and to evaluate the relative contribution of the various exposure routes to the observed biomarker levels [12-14].

The objective of this article was to review the kinetic parameters of organophosphate and pyrethroid pesticides and compare measurements of biomarkers of these pesticide exposures among children across several studies. The results and analysis presented in this article were developed as a component of a larger analysis of studies conducted and funded by EPA to identify key factors that influence children's exposure to pesticides along all relevant pathways. The report Important Exposure Factors for Children: an Analysis of Laboratory and Observational Field Data Characterizing Cumulative Exposure to Pesticides [15] compares results across studies to identify trends and reveals areas where progress has been made in reducing uncertainties. This article consolidates urinary biomarkers measurements from both large- and small-scale observational studies to identify trends that otherwise may not be apparent in analyses of the individual studies.

\section{Background}

\subsection{Review of the Toxicokinetics of Organophosphate and Pyrethroid Pesticides}

Organophosphate (OP) pesticides are typically composed of an $O, O$-dialkyl substituted phosphate, phosphorothioate, or phosphorodithioate moiety and an organic group [16]. The organophosphates are more water soluble and have higher vapour pressures than the chlorinated pesticides that they replaced [17]. Pyrethroids are synthetic analogs of the naturally occurring pyrethrins, which are esters of a substituted cyclopropanecarboxylic acid and a substituted cyclopentenolone alcohol. Variations of the substituent groups on the acid and alcohol moieties increase stability and decrease volatility [18]. Some understanding of organophosphate and pyrethroid pesticide toxicokinetics is necessary to meaningfully compare the urinary biomarker concentrations presented here with environmental and dietary concentrations. Despite extensive usage of pesticides, remarkably little information on kinetic parameters describing absorption and elimination in humans is available from the scientific literature. Reported parameters extracted from the literature are summarized in Table 1. While not specifically addressed in this article, pyrethroids generally have lower vapor pressures and higher octanol/water partition coefficients than organophosphates pesticides, resulting in a tendency to favor the particulate phase at room temperature and to partition into organic matter (such as housedust). This not only affects translocation inside the home, but also can influence transfer mechanisms important for exposure as well and absorption into the body. 
Table 1. Absorption and elimination characteristics for pesticides and urinary biomarkers of pesticide exposure.

\begin{tabular}{|c|c|c|c|c|c|c|}
\hline \multirow{2}{*}{ Compound } & \multicolumn{3}{|c|}{ Absorption of Parent Compound } & \multicolumn{3}{|c|}{ Elimination of Metabolites } \\
\hline & Oral & Dermal & Inhalation & Oral & Dermal & Inhalation \\
\hline Chlorpyrifos & $\begin{array}{l}\text { Volunteer studies: } 70 \% \text { of oral dose } \\
\text { excreted in urine as TCPy [19], } 93 \% \\
\text { of oral dose excreted in urine as } \\
\text { dialkyl-phosphates [20]. }\end{array}$ & $\begin{array}{l}\text { Volunteer studies: } 1.3 \% \text { of dermal } \\
\text { dose excreted in urine as TCPy [19]. } \\
1 \% \text { of dermal dose excreted as } \\
\text { dialkyl-phosphates [20], } 1.2-4.3 \% \text { of } \\
\text { dermal dose excreted as TCPy [21]. }\end{array}$ & No Information. & $\begin{array}{l}\text { Volunteer study, } 27 \mathrm{~h} \\
\text { oral [19]. Volunteer } \\
\text { study, approx } 15.5 \mathrm{~h} \\
\text { oral [20]. }\end{array}$ & $\begin{array}{l}\text { Volunteer study, } 27 \mathrm{~h} \\
\text { dermal [19]. Volunteer } \\
\text { study, approx } 30 \mathrm{~h} \text { dermal } \\
\text { [20]. Volunteer study, } \\
\text { approx } 41 \mathrm{~h} \text { dermal [21]. }\end{array}$ & No Information. \\
\hline Diazinon & $\begin{array}{l}\text { Human oral absorption approx. } \\
60 \%[22] . \text { Default oral absorption } \\
\text { factor of } 0.85[23] .\end{array}$ & $\begin{array}{l}\text { Human dermal absorption rate: } \\
456 \mathrm{ng} / \mathrm{cm}^{2} / \mathrm{h}[22]\end{array}$ & No Information. & $\begin{array}{l}\text { Human study, } 2 \mathrm{~h} \\
\text { oral [22]. }\end{array}$ & $\begin{array}{l}\text { Human study, } 9 \mathrm{~h} \\
\text { dermal [22]. }\end{array}$ & No Information. \\
\hline $\begin{array}{l}\text { Pyrethroids } \\
\text { (as a group) }\end{array}$ & $\begin{array}{l}\text { Absorption is incomplete, minimum } \\
\text { estimate } 40-60 \% \text {, but first- pass } \\
\text { metabolism may underestimate } \\
\text { absorption [24]. }\end{array}$ & $\begin{array}{l}<2 \% \text { of the applied dermal dose is } \\
\text { absorbed, rate of absorption much } \\
\text { slower than by the oral or inhaled } \\
\text { routes; may be stored in skin and } \\
\text { then slowly released into the systemic } \\
\text { circulation [24]. }\end{array}$ & $\begin{array}{l}\text { Rapidly absorbed in } \\
\text { humans following } \\
\text { inhalation, but no } \\
\text { estimates of fraction } \\
\text { absorbed are } \\
\text { available [24]. }\end{array}$ & \multicolumn{3}{|c|}{$\begin{array}{l}\text { Elimination appears to follow first-order kinetics, with elimination half-times } \\
\text { in humans ranging from } 6.4 \text { to } 16.5 \text { hours, depending upon the specific } \\
\text { pyrethroid and exposure route studied [24]. }\end{array}$} \\
\hline Permethrin & $\begin{array}{l}\text { Oral absorption factor of } 0.70 \\
\text { suggested [25]. }\end{array}$ & $\begin{array}{l}\text { Poor dermal absorption: } \sim 2 \% \text { of } \\
\text { applied dose absorbed } / 24 \mathrm{~h}[26] \\
7.5 \% \text { (scalp) and } 1.9 \% \text { (forearm) of } \\
\text { applied dose [27]. }\end{array}$ & No Information. & No Information. & No Information. & No Information. \\
\hline Cyfluthrin & No Information. & No Information. & $\begin{array}{l}\text { Human data suggest } \\
\sim 15 \% \text { absorption [28]. }\end{array}$ & $\begin{array}{l}\text { Human oral dosing } \\
\text { produced } \mathrm{t}-1 / 2 \text { of } \\
6.4 \mathrm{~h}[28]\end{array}$ & No Information. & $\begin{array}{l}\text { Human } 1 / 2 \text {-lives of } \\
6.9 \mathrm{~h} \text { (c-DCCA), } \\
6.2 \mathrm{~h} \text { (t-DCCA), } \\
5.3 \mathrm{~h} \text { (FPBA) [28]. }\end{array}$ \\
\hline Cypermethrin & $\begin{array}{l}\text { Human volunteer study } 27-57 \% \\
\text { (mean } 36 \% \text { ) cypermethrin } \\
\text { absorbed [29]. }\end{array}$ & No Information. & No Information. & $\begin{array}{l}\text { Human oral dosing, } \\
\text { urinary metabolites } \\
\text { have mean } 1 / 2 \text {-life } \\
\text { of } 16.5 \mathrm{~h} \mathrm{[29].}\end{array}$ & $\begin{array}{l}\text { Human dermal dosing, } \\
\text { excretion rates peaked at } \\
12-36 \mathrm{~h} \text {, mean } 1 / 2-\text { life was } \\
13 \mathrm{~h} \mathrm{[29].}\end{array}$ & No Information. \\
\hline
\end{tabular}




\subsection{Absorption}

Following inhalation, absorption takes place in the alveolar region of the respiratory tract, where contaminants diffuse passively through the thin alveolar membrane and are absorbed into the bloodstream [30]. Inhalation studies with a variety of gases have shown that even the most efficiently absorbed low molecular weight, highly water soluble compounds rarely exceed $70 \%$ uptake [31]. No studies reporting the fraction of organophosphate pesticides absorbed through inhalation were found, but Oberst et al. [32] reported that close to $70 \%$ of sarin, a structurally related organophosphate cholinesterase inhibitor was absorbed. For pyrethroids, Leng et al. [28] reported that only about 16\% of cyfluthrin was absorbed through inhalation, but no estimates for other pyrethroids are available.

The importance of the dietary contribution to aggregate exposure among infants and young children is well known [25], but few studies have investigated what fraction of ingested pesticide residue is absorbed. For organophosphates, Nolan et al. [19] estimated 70\% absorption of chlorpyrifos based on urinary 3,5,6-trichloro-2-pyridinol (TCPy), whereas others estimated $60 \%$ to $93 \%$ absorption based on dialkylphosphate (DAP) metabolites [20,22]. Diet reportedly affects absorption [33]. As for pyrethroids, Woollen et al. [29] estimated that 27-57\% of cypermethrin was absorbed, while Eadsforth and colleagues [34,35] estimated $45-49 \%$ and $72-78 \%$ for the cis and trans isomers, respectively.

Dermal absorption in the residential environment is typically believed to be low due to loss by washing, evaporation, or exfoliation [36]. For organophosphate pesticides, absorption of chlorpyrifos was estimated, based on its primary metabolite TCPy, to be $1.28 \%$ of an applied dose of $4 \mathrm{mg} / \mathrm{cm}^{2}$ (over $12-20 \mathrm{~h}$ ) [19], and $1.2 \%$ and $4.3 \%$ of applied doses of 0.15 and $0.05 \mathrm{mg} / \mathrm{cm}^{2}$ (over $4 \mathrm{~h}$ ), respectively [21]. Absorption of both chlorpyrifos and diazinon was estimated to be about $1 \%$ of applied doses of about 0.4 and $1.3 \mathrm{mg} / \mathrm{cm}^{2}$ (over $8 \mathrm{~h}$ ), respectively, based on DAP metabolites [20,22]. A much higher absorption fraction was reported for malathion applied at a much lower dose $\left(4 \mu \mathrm{g} / \mathrm{cm}^{2}\right)$ [36], suggesting that absorption may be inversely related to applied dose. Large differences were reported by anatomical area [37] and among individuals [36]. For pyrethroids, Bartelt and Hubbell [26] found only about $2 \%$ of applied permethrin to be absorbed within $24 \mathrm{~h}$. Wester et al. [38] observed that approximately $2 \%$ (forearm) and 7.5\% (scalp) of radiolabeled pyrethrin, applied at a $\mu \mathrm{g} / \mathrm{cm}^{2}$ level, were absorbed. ATSDR [24] has concluded that for pyrethroids in general, $<2 \%$ of the applied dermal dose is absorbed, at a rate much slower than the rate of absorption by the oral or inhaled routes. However, since the applied dermal dosing studies were performed using relatively high loadings and since absorption decreases with increasing dermal loadings, the low values obtained for dermal absorption may be an artifact of study design and may underestimate absorption at the very low levels measured in field studies [27]. On the other hand, particle-bound residues, particularly pyrethroids, may also have a reduced potential for dermal absorption, as a consequence of being bound to the particle.

Due to the paucity of available information on absorption from human studies, simple default values based on human studies, animal studies, and conservative assumptions are often required. For young children (ages 1-6) the following route-specific absorption is often assumed: $50-100 \%$ for inhalation, $50 \%$ for ingestion, and 1-3\% for dermal. In addition, a daily intake of $100 \mathrm{mg}$ of house dust is assumed for indirect ingestion [39]. These absorption assumptions are a source of substantial uncertainty in route-specific intake estimates. 


\subsection{Distribution and Metabolism}

Once in the bloodstream, organophosphate and pyrethroid pesticides are rapidly distributed and metabolized. With OP pesticides, hydrolytic cleavage of the ester bond yields one dialkyl phosphate (DAP) metabolite and one organic group moiety [16]. Dimethyl OPs (including malathion, phosmet, and azinphos-methyl) produce dimethyl metabolites and diethyl OPs (including chlorpyrifos and diazinon) produce diethyl metabolites [40]. The organic group metabolites 2-isopropyl-6-methyl-4pyrimidinol (IMP) and 3,5,6-trichloro-2-pyridinol (TCPy) are the primary metabolites for diazinon and chlorpyrifos, repectively.

Once absorbed, pyrethroids are rapidly metabolized by hydrolysis of the central ester linkage and oxidation of both acid and alcohol moieties, converting both moieties to carboxylic acids. Most of the current use pyrethroids have an alpha-cyano-3-phenoxybenzoxy or a 3-phenoxybenzoxy group as the alcohol moiety and produce 3-phenoxybenzoic acid (3-PBA) as the ester cleavage metabolite [41]. The 3-phenoxybenzoic acid (3-PBA) metabolite is common to 10 of the 18 pyrethroids registered in the United States, including permethrin, cypermethrin, deltamethrin, esfenvalerate [42]. Other benzoic acid metabolites analogous to 3-PBA are more specific and include 4-fluoro-3-phenoxybenzoic acid (4F3PBA) from cyfluthrin and 2-methyl-3-phenylbenzoic acid (MPA) from bifenthrin. These are not necessarily terminal metabolites; for example, as much as $38 \%$ of 3 -PBA has been reported by Woollen et al. [29] to undergo further oxidation to 3-(4'-hydroxyphenoxy) benzoic acid (4OH3PBA). Cleavage of current pyrethroids also typically produces dihalovinyl-substituted chrysanthemic acid derivatives. The chrysanthemic acid derivative cis-2,2-dibromovinyl-2,2-dimethyl-cyclopropane1-carboxylic acid (DBCA) is specific to deltamethrin while the cis- and trans- isomers of 2,2-dichlorovinyl-2,2-dimethyl- cyclopropane-1-carboxylic acid (DCCA) are common to permethrin, cypermethrin, and cyfluthrin.

\subsection{Excretion}

Both the OP and pyrethroid metabolites are rapidly eliminated in urine. Elimination appears to follow first-order kinetics, with elimination half-times in humans ranging from 2 to $41 \mathrm{~h}$ for OPs and from 6.4 to $16.5 \mathrm{~h}$ for pyrethroids, depending on both the compound and the route of exposure [21,22,24]. The elimination half-life of about $8 \mathrm{~h}$ reported for 3-PBA among workers exposed to cypermethrin [43] suggests that $88 \%$ of the metabolite is excreted within the first $24 \mathrm{~h}$ following exposure.

Time to peak excretion of urinary OP pesticide metabolites depends on the route of absorption [20-22]. Peak excretion is observed to occur 6 to $24 \mathrm{~h}$ later when exposure is by the dermal route compared to when exposure is by the oral route, largely because of route-specific differences in absorption following exposure. Peak excretion may occur as late as $48 \mathrm{~h}$ following dermal exposure, as observed among volunteers performing scripted activities featuring extensive contact with a treated surface [44]. Extended peak excretion times suggest that chlorpyrifos may be retained by the skin and may remain systemically available for prolonged periods [21]. 


\section{Methods}

\subsection{Observational Exposure Measurement Studies}

Several studies were conducted or funded by EPA over the past decade to investigate children's exposure to environmental contaminants (Table 2). The studies, which included measurements of common residential use pesticides in environmental exposure media as well as in biological media, included: Minnesota Children's Pesticide Exposure Study ("MNCPES"); Children's Total Exposure to Persistent Pesticides and Other Persistent Organic Pollutants ("CTEPP"); Biological and Environmental Monitoring for Organophosphate and Pyrethroid Pesticide Exposures in Children Living in Jacksonville, Florida ("JAX"); Center for the Health Assessment of Mothers and Children of Salinas Quantitative Exposure Assessment Study ("CHAM-QEA"); Children's Pesticide Post-Application Exposure Study (“CPPAES”); Pilot Study Examining Translocation Pathways Following a Granular Application of Diazinon to Residential Lawns ("PET"); Dietary Intake of Young Children ("DIYC"). While not focused on children, the National Human Exposure Assessment Survey in Arizona ("NHEXAS-AZ") also provided useful data.

The studies took place in private residences and in child care centers and have been grouped as either large observational field studies (NHEXAS-AZ, MNCPES, CTEPP) or small pilot-scale observational studies (JAX, CPPAES, DIYC, and CHAM-QEA). The large observational field studies had a regional focus. A broad suite of chemical contaminants, including organophosphate and pyrethroid pesticides and their metabolites, were typically measured in multiple environmental media and in urine. Some of the small pilot-scale studies included measurements of multiple chemicals in multiple media in locations either with year-round residential pesticide use (JAX) or in close proximity to agricultural fields (CHAM-QEA). Other pilot-scale studies focused on a single compound (CPPAES, DIYC, PET).

Information on recruitment was reported in detail in articles presenting results from the individual studies. All studies involving children were observational research studies, as defined by the regulatory requirements set forth in EPA's human subjects regulations (40 CFR Part 26.402). All study protocols regarding recruitment and treatment of participants, including procedures to obtain the assent of the children and informed consent of their parents or guardians, were reviewed and approved by independent institutional review boards (IRB) and reviewed by the EPA to assure compliance with the Federal Policy for the Protection of Human Subjects ("the Common Rule").

\subsection{Urine Sample Collection}

All urine samples were collected exclusively at the children's homes except for the CTEPP study, in which urine samples were also collected at their daycare centers. Urine collection preceded and followed outdoor turf applications in the PET study and routine professional indoor applications in the DIYC and CPPAES studies (Table 2). Spot urine samples, mainly first morning voids, were collected using age-appropriate methods including under-toilet seat bonnet (CTEPP, PET), collection cup (NHEXAS-AZ, MNCPES), diaper insert (DIYC), and "potty chair" (CPPAES). 
Table 2. Summary of the children's urinary biomarker collection methods.

\begin{tabular}{|c|c|c|c|c|c|c|c|c|}
\hline Study & $\mathbf{N}$ & $\begin{array}{c}\text { Age } \\
\text { Range }\end{array}$ & Sample Collection & Collection Strategy & $\begin{array}{c}\text { Pesticide } \\
\text { Application }\end{array}$ & Collection Frequency & $\begin{array}{c}\text { Analytes of } \\
\text { Interest }\end{array}$ & References \\
\hline $\begin{array}{l}\text { NHEXAS-AZ } \\
\text { (subset) }\end{array}$ & 21 & $\begin{array}{l}5 \text { to } 12 \\
\text { years }\end{array}$ & $\begin{array}{l}\text { December } 1995 \text { to } \\
\text { March } 1997\end{array}$ & Morning void & No & $\begin{array}{l}\text { Once (in 3-day } \\
\text { monitoring period) }\end{array}$ & $\begin{array}{l}\text { AM, MDA, } \\
\text { 1-Nap, TCPy }\end{array}$ & {$[45]$} \\
\hline MNCPES & 102 & $\begin{array}{l}3 \text { to } 13 \\
\text { years }\end{array}$ & Summer 1997 & Morning void & No & $\begin{array}{l}\text { Days } 3,5 \text {, and } 7 \text { of } \\
\text { sampling period }\end{array}$ & $\begin{array}{l}\text { AM, MDA, } \\
\text { 1-Nap, TCPy }\end{array}$ & {$[46]$} \\
\hline CTEPP-NC & 130 & $\begin{array}{l}2 \text { to } 5 \\
\text { years }\end{array}$ & July 2000 to March 2001 & $\begin{array}{c}\text { Morning void, } \\
\text { after lunch, after } \\
\text { dinner/before bedtime }\end{array}$ & No & Over a 48 -h period & $\begin{array}{l}\text { 2,4-D, TCPy, } \\
\text { PCP }\end{array}$ & {$[47,48]$} \\
\hline СТЕРP-OH & 127 & $\begin{array}{l}2 \text { to } 5 \\
\text { years }\end{array}$ & $\begin{array}{l}\text { April } 2001 \text { to } \\
\text { November } 2001\end{array}$ & $\begin{array}{l}\text { Morning void, after } \\
\text { lunch, after dinner/ } \\
\text { before bedtime }\end{array}$ & No & Over a 48 -h period & $\begin{array}{c}\text { 2,4-D, TCPy, } \\
\text { 3-PBA, PCP, } \\
\text { IMP }\end{array}$ & {$[48-50]$} \\
\hline CHAM-QEA & 20 & $\begin{array}{l}6 \text { to } 24 \\
\text { months }\end{array}$ & June to October 2002 & $\begin{array}{l}\text { One overnight and } \\
\text { one spot sample }\end{array}$ & $\begin{array}{l}\text { No, but incidental } \\
\text { exposure from } \\
\text { proximity to farms }\end{array}$ & Once & DAPs & {$[51]$} \\
\hline JAX & 9 & $\begin{array}{l}4 \text { to } 6 \\
\text { years }\end{array}$ & August to October 2001 & Morning void & $\begin{array}{c}\text { Yes, indoor as } \\
\text { applied by residents }\end{array}$ & Once & $\begin{array}{c}\text { TCPy, IMP, } \\
\text { 3-PBA }\end{array}$ & {$[52]$} \\
\hline CPPAES & 10 & $\begin{array}{l}2 \text { to } 4 \\
\text { years }\end{array}$ & $\begin{array}{l}\text { April } 1999 \text { to } \\
\text { March } 2001\end{array}$ & Morning void & $\begin{array}{c}\text { Yes, indoor } \\
\text { professional-applied } \\
\text { 'crack \& crevice' }\end{array}$ & $\begin{array}{l}\text { Pre-application and days } 1,2,3 \\
5,7,9, \text { and } 11 \text { post-application }\end{array}$ & TCPy & {$[53]$} \\
\hline PET & 6 & $\begin{array}{l}5 \text { to } 12 \\
\text { years }\end{array}$ & Spring 2001 & Morning void & $\begin{array}{c}\text { Yes, outdoor } \\
\text { resident-applied turf } \\
\text { treatment }\end{array}$ & $\begin{array}{c}\text { Pre-application and days } \\
1,2,4 \text {, and } 8 \text { post-application }\end{array}$ & IMP & {$[54]$} \\
\hline DIYC & 3 & $\begin{array}{l}1 \text { to } 3 \\
\text { years }\end{array}$ & $\begin{array}{c}\text { November } 1999 \text { to } \\
\text { January } 2000\end{array}$ & $\begin{array}{l}\text { Morning void and } \\
\text { other spot samples }\end{array}$ & $\begin{array}{c}\text { Yes, indoor, } \\
2 \text { professional } \\
\text { 'crack \& crevice' and } \\
1 \text { resident treatment }\end{array}$ & Days 3,5 , and 7 post-application & IMP & {$[55]$} \\
\hline
\end{tabular}

1-Nap, 1-Naphthol; 2,4-D, 2,4-Dichlorophenoxyacetic acid; 3-PBA, 3-Phenoxybenzoic acid; AM, Atrazine Mercapturate; DAPs, Dialkyl phosphate metabolites;

IMP, 2-Isopropyl-6-methyl-4-pyrimidinol; MDA, Malathion Dicarboxylic Acid; PCP, Pentachlorophenol; TCPy, 3,5,6-trichloro-2-pyridinol. 
Sample collection was performed by the children's caregivers following protocols provided by the investigators. Chemical analysis of urinary pesticide metabolites in nearly all included studies was performed by the National Center for Environmental Health of the Centers for Disease Control and Prevention (CDC) in Atlanta, GA, using validated tandem mass spectrometry techniques [42,56-58]. Chemical analysis for the CTEPP study was performed by Battelle Memorial Institute using validated gas chromatography/mass spectroscopy techniques [59]. Chemical analysis for the DIYC was performed by RTI International using CDC methods.

\subsection{Pesticides and Their Metabolites}

Only selected organophosphate and pyrethroid metabolites that were measured in several of the studies of interest, namely, TCPy, IMP, and 3-PBA, are presented in this article. Several other insecticides and their metabolites were also measured in the studies (Table 2) but are not included in this analysis.

\subsection{Statistical Analysis}

All statistical analyses were performed using SAS version 8.0. Summary statistics generated for urinary biomarkers common to several studies were reviewed and compared. Spot measurements of urinary pesticide biomarkers among children 6 to 12 years old from the 1999-2000 and 2001-2002 cycles of the National Health and Nutrition Examination Survey (NHANES) [60], an ongoing assessment of the exposure of the U.S. population to environmental chemicals, were also included for comparison.

\subsubsection{Estimates of Variance Components}

The relationship between a single urinary metabolite measurement and the mean of a series of measurements from the same participant was evaluated among a subset of non-composited CTEPP samples collected over 48 hours. The reliability of a single measurement in representing a true longer-term average is a function of the variability of a series of measurements [61]. More specifically, it is a function of the magnitude of the intra-person component of variance with respect to the total variance, or the intraclass correlation coefficient of reliability (ICC). An ICC of at least 0.80 is generally considered to indicate good reliability [61], signifying that the values are consistent from sample-to-sample and that a single measurement sufficiently represents the average of the series of measurements over a specific time period.

The following equation was used to estimate the intraclass correlation coefficient of reliability:

$$
I C C=\hat{\sigma}_{B}^{2} /\left(\hat{\sigma}_{B}^{2}+\hat{\sigma}_{W}^{2}\right)
$$

where the inter-person variance $\sigma_{B}^{2}$ and the intra-person variance $\sigma_{W}^{2}$ were estimated from a random effects model using mixed effects regression. Between- and within-person fold-ranges $\left({ }_{B} R_{0.95}\right.$ and ${ }_{\mathrm{w}} \mathrm{R}_{0.95}$ ) were estimated following Rappaport [62] as:

$$
{ }_{B} R_{0.95}=e^{3.92 \hat{\sigma}_{B}} \text { and }{ }_{W} R_{0.95}=e^{3.92 \hat{\sigma}_{W}}
$$


Variance estimates were repeated with urine values adjusted for specific gravity of the sample ( $\left.\mathrm{SG}_{\text {sample }}\right)$ using a target value $\left(\mathrm{SG}_{\text {target }}\right)$ of 1.022 [63] and the following equation [64]:

$$
\mathrm{SG} \text {-adjusted value }=\text { value } \times\left(\mathrm{SG}_{\text {target }}-1.000\right) /\left(\mathrm{SG}_{\text {sample }}-1.000\right)
$$

\subsubsection{Estimates of Route-Specific Exposure}

Route-specific exposure and subsequent intake was estimated using CTEPP data by combining concentrations measured in exposure media with rudimentary individual-level time activity information and default exposure factors $[47,65]$.

\section{Results and Discussion}

\subsection{Summary Statistics for Urinary Biomarker Levels}

Several pesticide metabolites were frequently detected. The chlorpyrifos metabolite, TCPy, was detected above the LOD in over $90 \%$ of the children's urine samples in all listed studies. The pyrethroid metabolite, 3-PBA, was detected at frequencies of over $60 \%$ in the CTEPP-OH samples and $100 \%$ of the JAX samples, the only two studies in which it was measured. IMP was detected at $77 \%$, $100 \%$, and $0 \%$ in the PET, DIYC, and JAX studies, respectively. All measurements of IMP in CTEPP-OH were deemed questionable due to analytical interferences and excluded from this analysis. The detection frequency and the concentrations at the median and 95th percentiles for each urinary metabolite are presented by study in Table 3. Distributions of the urinary metabolite concentrations are depicted with box-and-whisker plots in Figure 1. The median urinary TCPy concentrations were fairly similar across studies, with a fold range of only about 2.4 between the lowest $(5.1 \mathrm{ng} / \mathrm{mL}$ for CTEPP-NC) and the highest $(12.0 \mathrm{ng} / \mathrm{mL}$ for NHEXAS-AZ) studies. The median urinary TCPy concentrations in CPPAES, a study with known and monitored applications of chlorpyrifos, did not differ substantially from the medians in the large-scale studies. Among the large-scale studies, there was little difference in urinary TCPy concentrations measured in the North Carolina and Ohio segments of CTEPP, but the concentrations from Minnesota and Arizona were distinctly higher (all unweighted). Higher levels in the Minnesota and Arizona studies may reflect the greater use of chlorpyrifos at the time that the two studies were conducted, and particularly with MNCPES, an intentional oversampling of pesticide-using households [46]. The median TCPy values observed in all EPA studies (ranging from 5.1 to $12 \mathrm{ng} / \mathrm{mL}$ ) were higher than median for children under 12 years old in the combined 1999-2002 NHANES release $(2.8 \mathrm{ng} / \mathrm{mL})$. The median TCPy values were also higher than those reported for children $1-6$ years of age $(n=60)$ in eastern North Carolina farm-worker households $(2.47 \mathrm{ng} / \mathrm{mL}$, [66], on par with the median of $9.1 \mathrm{ng} / \mathrm{mL}$ reported for 13 children aged 2-5 years from Washington State [67], and below the geometric mean of $16 \mathrm{ng} / \mathrm{mL}$ reported for 116 children under the age of 16 years living in Iowa farm and non-farm households [68]. 
Table 3. Summary statistics for the pesticide metabolites TCPy, IMP, and 3-PBA measured in the children's urine samples by study (ng/mL). NHANES results are included for comparison.

\begin{tabular}{|c|c|c|c|c|c|c|c|c|c|c|c|c|c|c|}
\hline & Study & Group & $\mathbf{n}$ & \%Det & Mean & SD & GM & GSD & Min & 25th & $50^{\text {th }}$ & 75th & 95th & Max \\
\hline \multirow{7}{*}{ ТCPy } & NHEXAS-AZ & $\leq 12$ years & 21 & 100 & 12 & 7.6 & 9.3 & 2.2 & 2.0 & 5.7 & 12 & 14 & 26 & 30 \\
\hline & MNCPES & All & 263 & 92 & 9.2 & 7.7 & 6.6 & 2.3 & $<1.4$ & 4.0 & 7.2 & 12 & 23 & 45 \\
\hline & CTEPP-NC & All & 129 & 98 & 7.5 & 10 & 5.5 & 2.1 & $<1.0$ & 3.8 & 5.3 & 8.4 & 16 & 100 \\
\hline & CTEPP-OH & All & 123 & 100 & 5.9 & 3.5 & 4.9 & 1.9 & 1.2 & 3.1 & 5.2 & 7.8 & 12 & 15 \\
\hline & JAX & All & 9 & 100 & 11 & 6.4 & 9.1 & 2.1 & 2.9 & 7.5 & 9.8 & 15 & 21 & 21 \\
\hline & CPPAES & All & 81 & 93 & 8.0 & 4.7 & 6.4 & 2.1 & $<1.0$ & 4.5 & 7.7 & 11 & 18 & 20 \\
\hline & NHANES & $\leq 12$ years & 1245 & 90 & 4.7 & 6.1 & 2.6 & 3.2 & $<0.4$ & 1.3 & 2.8 & 6.0 & 15 & 64 \\
\hline \multirow{3}{*}{ 3-PBA } & CTEPP-OH & All & 126 & 68 & 0.81 & 3.0 & 0.38 & 2.6 & $<0.20$ & $<0.20$ & 0.32 & 0.69 & 1.9 & 34 \\
\hline & JAX & All & 9 & 100 & 19.6 & 33 & 3.9 & 7.5 & 0.39 & 0.76 & 2.2 & 29 & 99 & 99 \\
\hline & NHANES & $\leq 12$ years & 679 & 79 & 1.4 & 10 & 0.36 & 3.7 & $<0.10$ & 0.13 & 0.34 & 0.78 & 3.8 & 254 \\
\hline \multirow{3}{*}{ IMP } & PET & All & 30 & 77 & 1.3 & 1.6 & 0.75 & 2.8 & $<0.22$ & 0.39 & 0.62 & 1.5 & 5.5 & 6.2 \\
\hline & DIYC & All & 41 & 100 & 9.0 & 6.9 & 7.1 & 2.0 & 1.7 & 4.4 & 7.1 & 10 & 27 & 29 \\
\hline & NHANES & $\leq 12$ years & 1220 & 15 & $\mathrm{NC}$ & $\mathrm{NC}$ & $\mathrm{NC}$ & $\mathrm{NC}$ & $<0.7$ & $<0.7$ & $<0.7$ & $<0.7$ & 3.0 & 145 \\
\hline
\end{tabular}


Figure 1. Box-and-whisker plots comparing the urinary TCPy, 3-PBA, and IMP concentrations across studies. NHANES results (6-12 year olds) included for comparison.

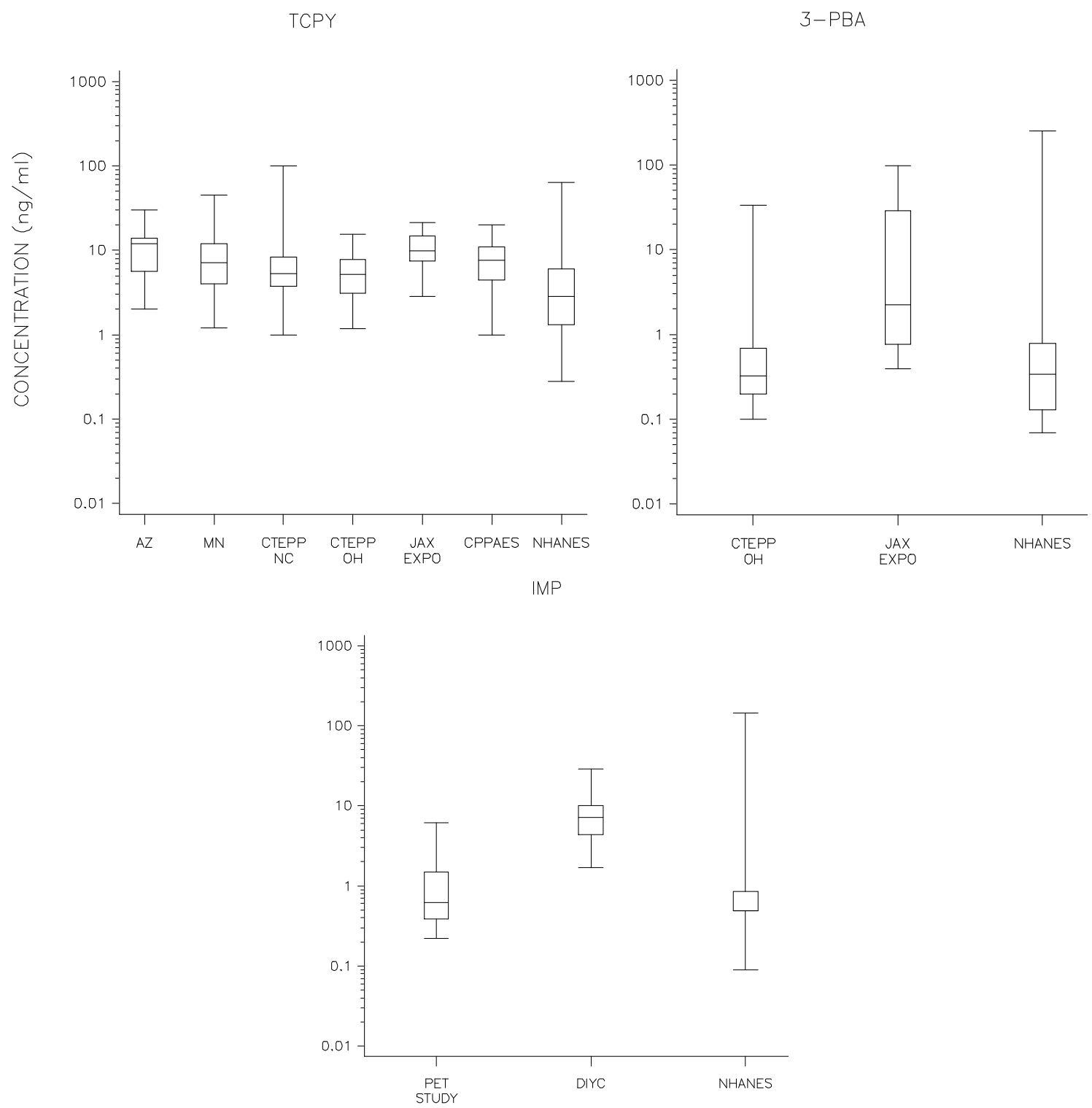

The median urinary concentrations varied more dramatically for 3-PBA and IMP than for TCPy. The median 3-PBA level measured in JAX $(2.2 \mathrm{ng} / \mathrm{mL})$, in a location with elevated rates of pesticide use [69], was more than seven times higher than the median in CTEPP-OH $(0.3 \mathrm{ng} / \mathrm{mL})$. The median level in CTEPP-OH is consistent with levels among elementary school-age children in and around Seattle, WA $(0.45 \mathrm{ng} / \mathrm{mL})$ [70], among children in the population-based NHANES survey in the U.S. $(0.32 \mathrm{ng} / \mathrm{mL})$ [60] and GerES IV in Germany $(0.29 \mathrm{ng} / \mathrm{mL})$ [71]. For IMP, the median level in the DIYC study $(7.1 \mathrm{ng} / \mathrm{mL})$ was ten times higher than in the PET study (0.62), reflecting that measurements followed indoor pesticide applications in the former and outdoor applications in the latter. Measurements from both studies fell within the range found in NHANES.

The box-and-whisker plots presented in Figure 1 are also useful for comparing the different metabolites against each other. Across studies, urinary TCPy concentrations (with medians ranging from 5.1 to 12) appear to be about an order of magnitude higher than the urinary 3-PBA concentrations 
(medians ranging from 0.3 to 2.2). Concentrations of IMP (medians ranging from 0.62 to 7.1 ) were roughly in between the concentrations of 3-PBA and TCPy, with concentrations in DIYC in the TCPy range. The relative magnitude of TCPy versus 3-PBA concentrations is similar to that found in the nationwide NHANES (2.8 versus 0.34 ) and among children in North Carolina farm-worker households (2.47 versus 0.07 ) [66]. This difference suggests that the study populations experienced greater overall exposure to chlorpyrifos (and environmental TCPy) than to the pyrethroids that are metabolized to 3-PBA (and environmental 3-PBA). However, since chlorpyrifos and diazinon were deregistered by the EPA for most residential uses in 2000 and 2004, respectively [72,73], there is an expectation that non-dietary organophosphate exposures have decreased over time, a trend recently documented among heavy residential pesticide users $[74,75]$.

\subsection{Evidence of Pesticide Applications in Urinary Concentrations}

Measurements in several studies allowed investigation of the utility of urinary biomarker levels in providing evidence of recent pesticide applications. Biomarker confirmation of pesticide application was stronger with 3-PBA and IMP than with TCPy. The median level of 3-PBA in CTEPP $(0.32 \mathrm{ng} / \mathrm{mL})$ was similar to that in NHANES $(0.34 \mathrm{ng} / \mathrm{mL})$, but the median 3-PBA value among children in JAX $(2.2 \mathrm{ng} / \mathrm{mL})$ was about seven times higher (Table 3$)$. The distribution of levels of IMP from the DIYC study (median $=7.1 \mathrm{ng} / \mathrm{mL}$ ) was about an order of magnitude higher than the distributions from the PET (median $=0.62 \mathrm{ng} / \mathrm{mL}$ ) or NHANES (median $<0.7 \mathrm{ng} / \mathrm{mL}$ ) studies. The relative magnitudes of the urinary IMP levels is in concordance with expectations based on the type of applications, as the participants of the DIYC study performed thorough indoor applications of diazinon while the participants in the PET study applied the insecticide outdoors on turf. Evidence of application, however, was absent in a study following crack and crevice applications of chlorpyrifos in the CPPAES study [53]. In that study, the intensity of application was described as either high $(\mathrm{n}=7)$ or low $(\mathrm{n}=3)$, based on the total amount of active ingredient dispensed. Although mean air concentrations resulting from "high" applications were five orders of magnitude higher than those resulting from "low" applications, the urinary TCPy concentrations were not much different for the children in the high versus low application groups [53]. Crack and crevice type applications of chlorpyrifos at these homes did not substantially increase the children's urinary TCPy concentrations. In fact, the median urinary TCPy concentration for children in the "high" application group was higher one day before application than on the first two days following application. Furthermore, the concentration-time profiles for urinary TCPy levels did not mirror the environmental concentration time profiles (Figure 2). The lack of an observable effect on urine concentrations may be related to exposure to environmental TCPy or to chlorpyrifos and TCPy through the dietary pathway [70,76], but neither of these potential contributions was evaluated in the study. 
Figure 2. Time profiles for chlorpyrifos in environmental media and TCPy concentrations in urine for all children in the CPPAES following crack and crevice treatment.
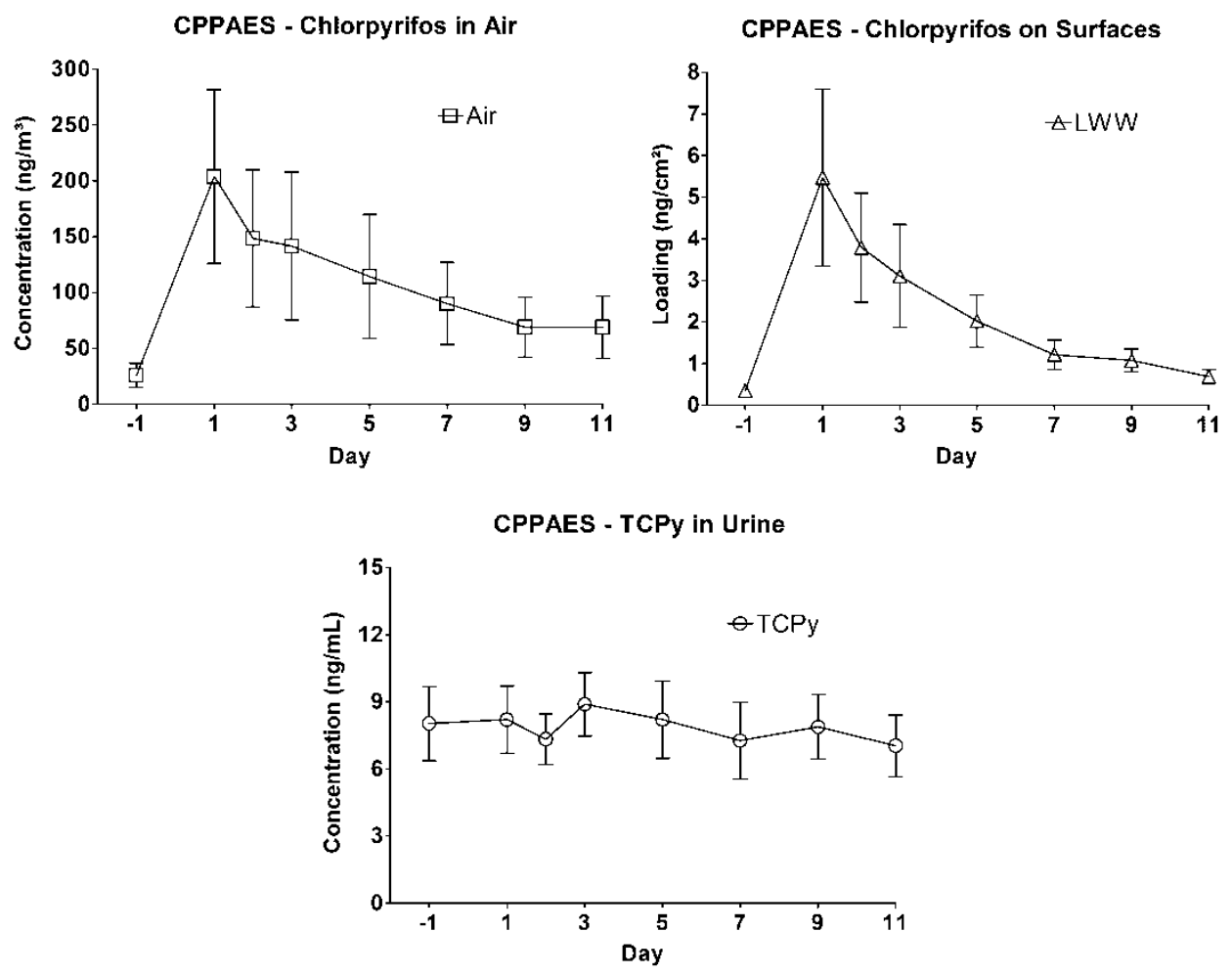

Change in urinary metabolite levels was also investigated with diazinon in the PET study with lawn applications [54] and the DIYC study with indoor applications. While no statistically significant difference in pre- and post-application urinary IMP concentrations was reported by the authors of the PET study, the time-concentration profile appears to show an observable decay in children's urinary biomarker concentrations in the eight days following the outdoor lawn application (Figure 3). The pattern among adults is not consistent with that among children, perhaps reflecting differences in exposure patterns between adults and children [77]. IMP concentrations in the first morning voids (FMV) of the DIYC children did not decay steadily over time, but behaved similarly to the adults in the PET study (data not shown). The difference between indoor and outdoor application may be a factor in the pattern changes.

Figure 3. Time-concentration profile for urinary IMP measurements among child and adult PET study participants following an outdoor granular turf pesticide application.
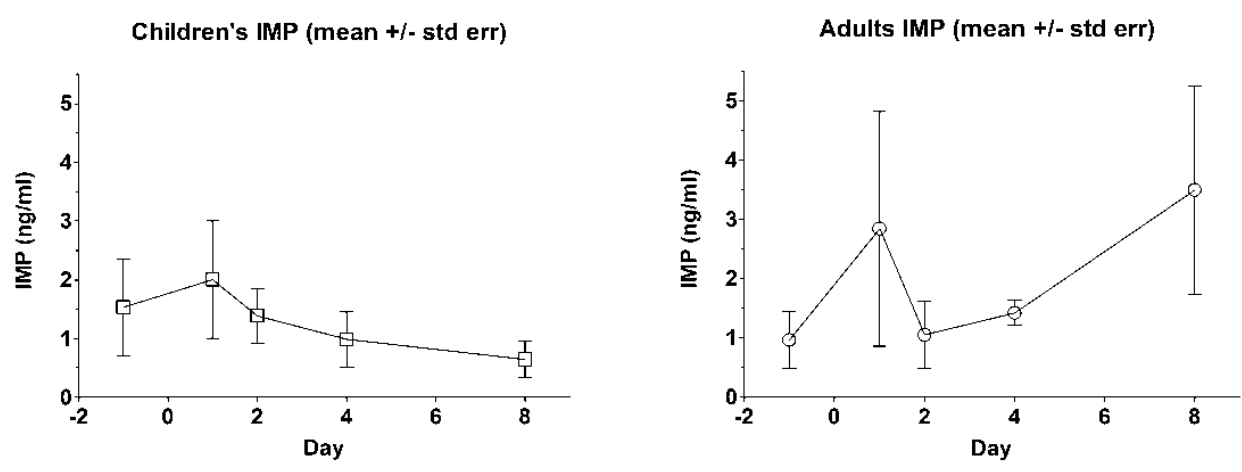


\subsection{Temporal Variability in Biomarker Measurements}

Spot urine measurements over 48 hours among CTEPP participants reporting a recent application of any pesticide (within seven days of field monitoring) show large sample-to-sample variability and large differences among individuals (Supplemental Figure S-1). Adjustment of urinary metabolite values by specific gravity did not meaningfully reduce within-person variability of TCPy. Intraclass correlation coefficients of reliability (ICC) and the within- and between-person geometric standard deviations (GSD) for urinary TCPy and 3-PBA concentrations in $\mathrm{NC}$ and $\mathrm{OH}$ children in the CTEPP study are provided in Table 4.

Table 4. Estimated between- and within-person fold-ranges $\left({ }_{b} \mathrm{R}_{0.95}\right.$ and $\left.{ }_{\mathrm{w}} \mathrm{R}_{0.95}\right)$ and Intraclass Correlation Coefficients (ICC) for logged urinary pesticide metabolite concentrations from children in the CTEPP study.

\begin{tabular}{|c|c|c|c|}
\hline Metabolite & Measure & NC Children & OH Children \\
\hline \multirow{3}{*}{$3-P B A$} & ${ }_{\mathrm{b}} \mathrm{R}_{0.95}$ & $-{ }^{\mathrm{b}}$ & 13 \\
& ${ }_{\mathrm{w}} \mathrm{R}_{0.95}$ & - & 5.6 \\
& $\mathrm{ICC}^{\mathrm{a}}$ & - & 0.69 \\
\hline \multirow{3}{*}{$\mathrm{TCPy}$} & ${ }_{\mathrm{b}} \mathrm{R}_{0.95}$ & 13 & 11 \\
& ${ }_{\mathrm{w}} \mathrm{R}_{0.95}$ & 6.5 & 14 \\
& $\mathrm{ICC}$ & 0.65 & 0.44 \\
\hline
\end{tabular}

${ }^{a}$ An ICC of 0.80 indicates that a single measurement reliably represents the average of a set of measurements. " "_-" = no data.

Reliability is a function of both interpersonal and intrapersonal variability and describes the degree to which a randomly selected single measurement represents the average of a set of measurements on a given individual over a specific time period [78]. The ICC can range from zero to one, with values near one indicating high reliability. A value of 0.80 is typically considered the benchmark above which a single measurement for an individual adequately represents his or her average. As an additional measure of variability, the between- and within-person $\mathrm{R}_{0.95}$, representing the fold-range containing the middle $95 \%$ of the participant-specific mean concentrations $\left({ }_{b} R_{0.95}\right)$ or of the repeated measurements for a given participant $\left({ }_{w} \mathrm{R}_{0.95}\right)$, respectively, were estimated. The urinary 3-PBA concentrations were slightly more consistent over time than the TCPy concentrations, as evidenced by a higher ICC. For the Ohio children, the ${ }_{\mathrm{w}} \mathrm{R}_{0.95}$ estimates indicate that $95 \%$ of the TCPy measurements for a single individual would be expected to have a 14-fold range, whereas a 5.6-fold range would be expected for the 3PBA measurements. Estimates of ICC suggest that spot sample measurements of neither 3-PBA nor TCPy concentrations exhibit sufficient consistency throughout the 48-h monitoring period to adequately rank the participants' exposure levels with a single measurement. Furthermore, large intrapersonal variability with respect to interpersonal variability can obscure relationships between a urinary biomarker result and a determinant of exposure (e.g., prior application, route of exposure) through attenuation of the regression coefficient [79,80]. An example of this with pesticide exposures among children can be found in Curwin et al. [81], where children's urinary pesticide levels generally had much higher intra-individual variability and greater attenuation of exposure relationships compared to adults. Similar ICCs ( 0.59 and 0.49 for $\mathrm{NC}$ and $\mathrm{OH}$, respectively) were observed for the herbicide 
2,4-dichlorophenoxyacetic acid (2,4-D) in the same cohort [48]; Meeker et al. [82] reported similar reliability for the carbaryl metabolite 1-naphthol (ICCs between 0.55 and 0.61 ) and much lower reliability for TCPy (ICCs between 0.15 and 0.21) among adult men in New England; and Egeghy et al. [83] reported somewhat lower reliability for TCPy $(0.40)$ among adults in Maryland. These results point to the need to understand urinary output in order to reduce the observed variability in spot samples [84].

Comparing FMV to other spot samples collected among the same subsample of CTEPP children (data not presented), the geometric mean of the FMV concentrations is substantially higher ( $45 \%$, $\mathrm{p}<0.001)$ than that of the non-FMV samples for TCPy. Higher FMV concentrations are likely the result of a combination of reduced urinary output at night and the timing of dietary exposures. The same analysis for 3-PBA found FMV to be only negligibly higher $(17 \%, \mathrm{p}=0.40)$. Since both compounds experienced the same accumulation time in the bladder, the reason for the discrepancy in the results is not entirely clear but may point to differences in exposure routes and patterns for the two parent compounds. A similar analysis was performed in the CHAM-QEA study, where concentrations in the overnight diapers of very young children (6 months to 2 years) were compared to concentrations in spot samples [51]. Median total dialkyl phosphate (DAP) metabolite concentrations were higher in the overnight samples compared to the spot samples (140 vs. $100 \mathrm{nmol} / \mathrm{L})$, but the authors reported that the difference was not statistically significant with a Wilcoxon rank sum test. Spot and overnight urine concentrations were significantly correlated in CHAM-QEA, with a Spearman rho of $0.48(\mathrm{p}<0.01)$ reported for total DAP metabolites [51].

Kissel et al. [67] investigated excretion patterns at various time points throughout the day for two nonspecific and three specific organophosphate metabolites among children approximately 4 years of age. They compared nighttime, FMV, lunchtime, and afternoon samples and reported that the concentrations were highly variable over the course of a single 24-h period. Employing a percent deviation approach to evaluate the correspondence of a single spot sample with average daily results, they found that FMV samples were the best predictors of estimated total daily excretion for the organophosphate metabolites. No similar analysis has been performed for pyrethroid metabolites. For organophosphates these analyses taken together suggest that although FMV samples may slightly overestimate exposure, they still provide a more reliable estimate than what would be available from samples collected at other times of the day.

\subsection{Relative Importance of Exposure Routes}

The relative importance of the dietary ingestion, indirect ingestion, dermal, and inhalation routes of exposure with respect to aggregate intake previously has been investigated through pharmacokinetic (PK) modeling in the DIYC study and through comparisons with biomarker levels in the DIYC, MNCPES, and CTEPP studies. Hu et al. [55] identified ingestion as the dominant route of exposure to diazinon among children using PK modeling. In an analysis of the MNCPES chlorpyrifos data, Clayton et al. [85] showed, using a mass balance approach, that dietary ingestion was a greater source of intake than inhalation. Similarly, Morgan et al. [59] determined that the primary route of intake for chlorpyrifos and permethrin among CTEPP children was dietary ingestion. Dietary ingestion as the dominant route of exposure to pesticides has been supported by other studies. For example, Lu and colleagues [76] substituted organic for conventional food to evaluate the importance of dietary 
exposure relative to other routes for children in the Seattle, WA area and reported that the contribution of chlorpyrifos from dietary sources far exceeded the contribution from the residential environment.

Curiously, when comparing dietary chlorpyrifos intake to the urinary biomarker concentrations, neither Clayton nor Morgan found strong associations. Clayton [85] reported that the association with urinary metabolite levels was much weaker for the dietary measurements $(r=0.22, p<0.05)$ than air concentrations $(r=0.42, p<0.01)$. Morgan's group [47] also reported poor correlation with dietary ingestion $(\mathrm{r}=0.12, \mathrm{p}>0.05)$. These results are similar to the correlation between estimated dietary intake of chlorpyrifos and urinary excretion of TCPy $(r=0.21, p<0.05)$ observed among adults in the NHEXAS-Maryland study using a similar algorithm [86]. In a subsequent publication, Morgan's group reported that the relationship between dietary chorpyrifos and urinary TCPy is obscured by concurrent multi-route exposure to the environmentally occurring metabolite [49]. Differences in absorption and elimination by route of absorption, as discussed in Section 2, may also obscure the relationship. Specifically, a combination of multi-route exposures of varying intensities, differences in time-topeak-excretion by route, and urine sample collection timing based on oral dosing studies may affect the relationship between external exposure and biomarker.

Another factor that may contribute to the poor correlations observed between dietary ingestion and urinary biomarkers may be great variability in indirect intake from hand-to-mouth contact among children [87]. As illustrated in Figure 4 using data from 85 CTEPP-OH participants with a complete set of air, dermal, dust, soil, and food measurements, the contribution of diet to aggregate cis-permethrin intake generally decreases (as percent of total contribution) as aggregate intake increases; conversely, indirect ingestion becomes increasingly important with increasing aggregate intake.

Figure 4. The contributions of inhalation, dermal absorption, indirect ingestion, and dietary ingestion to aggregate intake of cis-permethrin in CTEPP-OH $(n=85)$.

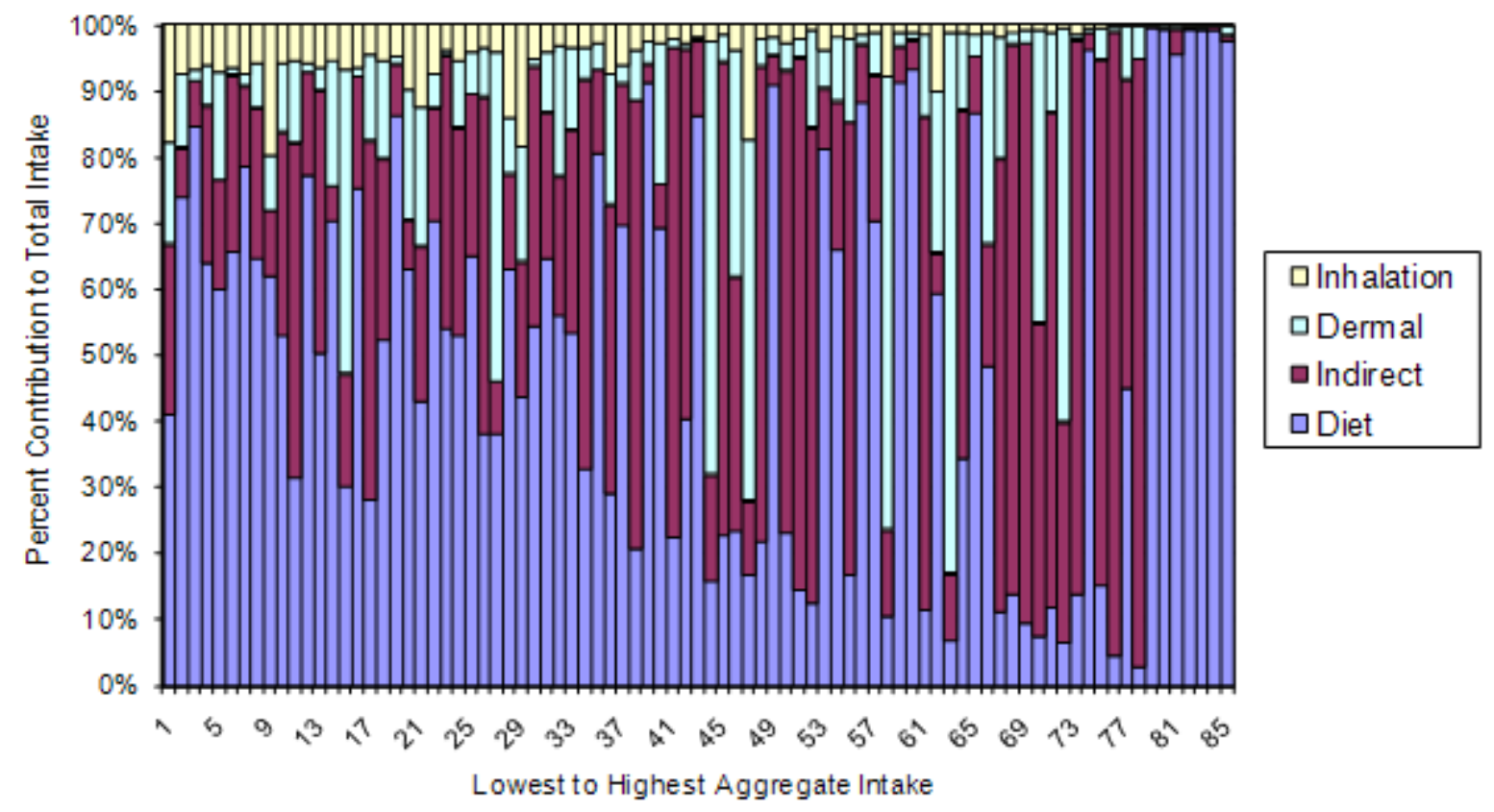


More specifically, except at the extremes of the distribution, the contribution from other routes overwhelms that of dietary as aggregate exposure increases. This analysis supports the finding by $\mathrm{Lu}$ et al. [88] that during episodes of relatively high exposures in the residential environment the contribution of pyrethroids from dietary exposure may be surpassed by other routes. In addition, the DIYC study revealed that the residential use of diazinon can contribute to the dietary route (supplementing the contribution of agricultural sources) through transfer from surfaces to food moderated by the behavioral activities exhibited by the child [55]. The overall result is that while dietary may be the primary source of intake on average, the importance of a particular exposure route is not consistent across individuals and may vary with exposure intensity. This may result in an attenuation of the association between the biomarker and a particular route of exposure. Thus, even if intake of environmentally occurring metabolites were negligible, a strong correlation with any one route may be difficult to observe.

\section{Conclusions}

While each pesticide exposure study performed or sponsored by the EPA typically measured the urinary metabolites of several different pesticides, few metabolites were commonly measured in multiple studies. Nonetheless, comparison of those metabolites across studies yields important insights. Distributions of urinary pesticide metabolite levels in children's observational studies were generally more similar across studies for the major metabolite of chlorpyrifos than for the metabolites of diazinon or the pyrethroid pesticides. Additionally, urinary TCPy concentrations were about an order of magnitude higher than the urinary 3-PBA concentrations. Together these observations suggest that children's exposures to chlorpyifos (and environmental TCPy) are more uniform across the population than are exposures to the other pesticides that were measured. This may reflect the quantity of chlorpyrifos in use at that period of time, ubiquity of its applications (including as structural termiticides and in agriculture), its transport mechanisms, and its persistence in indoor environments. While measurements of the urinary biomarker TCPy did not reflect known indoor crack and crevice applications of chlorpyrifos, urinary levels of IMP and 3-PBA performed better at capturing outdoor and indoor applications of diazinon and various pyrethroids. With most residential uses of chlorpyrifos and diazinon deregistered shortly after these studies were performed, and with the pyrethroids filling the market void, close attention should be paid to the trend over time in concentrations of urinary pyrethroid metabolites in future studies. Moreover, a greater variety of metabolites should be measured in future studies to better capture the breadth of pesticides that are currently being used.

Although dietary ingestion appeared to be primary route of exposure for both organophosphate and pyrethroid pesticides, the association between estimates of dietary intake and urinary biomarkers is weak. While this is largely the result of the presence of the metabolites in environmental media, there is also evidence that the relationship may be affected by route-specific differences in absorption and by route-specific contributions to total intake that are not consistent across individuals and may vary with exposure intensity. Exposure through multiple routes, as well as the timing of exposure and biomarker collection, may also contribute to the large variability that characterizes urinary biomarker measurements. Successive spot urine measurements showed large sample-to-sample variability in

addition to large differences among individuals. Concentrations in first morning void samples were 
higher than in other spot samples. The difference was much greater for TCPy than for 3-PBA for reasons that are not entirely clear but may point to differences in exposure routes and patterns for the two parent compounds and their environmental metabolites. Perhaps these results can lead to a standard protocol for collection of urine in observational pesticide exposure studies to minimize the variability introduced by these factors.

A currently ongoing study directly addresses the variability of urinary biomarkers of exposure to pyrethroids over time. The study is using statistical and modeling tools and other key information such exposure measurement, activity pattern, and kinetic parameter data to assess the quantitative relationships between urinary biomarkers and human exposures and internal doses to pyrethroids and to their degradates. The project will produce important biomonitoring data on the longitudinal variability and excretion rate of pyrethroid metabolites and other chemicals in urine over time. In addition, this information will be useful in understanding if single or multiple urine samples need to be collected in similar studies, and at frequency of collection would be ideal. The study will provide information regarding the effectiveness of several urine volume adjustment approaches for application in dose estimations using existing biomonitoring data and will determine the feasibility of using exposure reconstruction to estimate exposure in residential settings. Although the study is limited to adult volunteers, it is expected that the information produced will also be useful for the design of future studies of children's residential pesticide exposure.

\section{Acknowledgments}

We would like to acknowledge the many researchers and support staff who contributed by their design and implementation of the included studies. The authors gratefully acknowledge the time, effort, and constructive comments offered by Daniel M. Stout II, Miles Okino, and Kent Thomas. We are indebted to April Coan, who produced many of the graphics. We would especially like to thank all of the study participants who worked so generously with the researchers to help make these observational studies a success.

\section{Disclaimer}

The United States Environmental Protection Agency, through its Office of Research and Development, funded and managed the research described here under EPA Contracts 68-D-99-003 to the University of Arizona, 68-D-99-011 to Battelle Memorial Institute, and 68-D99-012 to Research Triangle Institute International, under Cooperative Agreements R821902 with Research Triangle Institute and Environmental and Occupational Health Sciences Institute (EOHSI) and CR827033 with EOHSI, and under EPA STAR Grant R825283 to the University of Minnesota. It has been subjected to Agency review and approved for publication. 


\section{References}

1. US EPA (US Environmental Protection Agency). Seven Priorities for EPA's Future; US Environmental Protection Agency: Washington, DC, USA, 2010; Available online: http://blog.epa.gov/administrator/2010/01/12/seven-priorities-for-epas-future/ (accessed on 23 May 2011).

2. Landrigan, P.J.; Carlson, J.E.; Bearer, C.F.; Cranmer, J.S.; Bullard, R.D.; Etzel, R.A.; Groopman, J.; McLachlan, J.A.; Perera, F.P.; Reigart, J.R.; et al. Children's health and the environment: A new agenda for prevention research. Environ. Health Perspect. 1998, 106, 787-794.

3. Cohen Hubal, E.A.; Sheldon, L.S.; Zufall, M.J.; Burke, J.M.; Thomas, K. The challenge of assessing children's residential exposure to pesticides. J. Expo. Anal. Environ. Epidemiol. 2000, 10, 638-649.

4. Ryan, P.B.; Burke, T.A.; Cohen Hubal, E.A.; Cura, J.J.; McKone, T.E. Using biomarkers to inform cumulative risk assessment. Environ. Health Perspect. 2007, 115, 833-840.

5. Wessels, D.; Barr, D.B.; Mendola, P. Use of biomarkers to indicate exposure of children to organophosphate pesticides: Implications for a longitudinal study of children's environmental health. Environ. Health Perspect. 2003, 111, 1939-1946.

6. Lowry, L.K. Biological exposure index as a complement to the TLV. J. Occup. Med. 1986, 28, 578-582.

7. Hulka, B.S.; Margolin, B.H. Methodological issues in epidemiologic studies using biological markers. Am. J. Epidemiol. 1992, 135, 200-209.

8. Rappaport, S.M.; Symanski, E.; Yager, J.W.; Kupper, L.L. The relationship between environmental monitoring and biological markers in exposure assessment. Environ. Health Perspect. 2005, 103, 49-53.

9. Bouchard, M.; Gosselin, N.H.; Brunet, R.C.; Samuel, O.; Dumoulin, M.J.; Carrier, G. A toxicokinetic model of malathion and its metabolites as a tool to assess human exposure and risk through measurements of urinary biomarkers. Toxicol. Sci. 2003, 73, 182-194.

10. Coble, J.; Arbuckle, T.; Lee, W.; Alavanja, M.; Dosemeci, M. The validation of a pesticide exposure algorithm using biological monitoring results. J. Occup. Environ. Hyg. 2005, 2, 194-201.

11. Droz, P.O.; Wu, M.M.; Cumberland, W.G.; Berode, M. Variability in biological monitoring of solvent exposure. I. Development of a population physiological model. Br. J. Ind. Med. 1989, 46, 447-460.

12. Gompertz, D. Assessment of risk by biological monitoring. Br. J. Ind. Med. 1981, 38, 198-201.

13. Egeghy, P.P.; Tornero-Velez, R.; Rappaport, S.M. Environmental and biological monitoring of benzene during self-service automobile refueling. Environ. Health Perspect. 2000, 108, 1195-1202.

14. Egeghy, P.P.; Hauf-Cabalo, L.; Gibson, R.; Rappaport, S.M. Benzene and naphthalene in air and breath as indicators of exposure to jet fuel. Occup. Environ. Med. 2003, 60, 969-976.

15. US EPA. Important Exposure Factors for Children: An Analysis of Laboratory and Observational Field Data Characterizing Cumulative Exposure to Pesticides; US Environmental Protection Agency: Washington, DC, USA, 2007; EPA/600/R-07/013. 
16. Barr, D.B.; Bravo, R.; Weerasekera, G.; Caltabiano, L.M.; Whitehead, R.D., Jr.; Olsson, A.O.; Caudill, S.P.; Schober, S.E.; Pirkle, J.L.; Sampson, E.J.; et al. Concentrations of dialkyl phosphate metabolites of organophosphorus pesticides in the U.S. population. Environ. Health Perspect. 2004, 112, 186-200.

17. Lamoreaux, R.J.; Newland, L.W. The fate of organophosphorus pesticides in the environment. Biol. Conserv. 1977, 11, 59-66.

18. Casida, J.E. Pyrethrum flowers and pyrethroid insecticides. Environ. Health Perspect. 1980, 34, 189-202.

19. Nolan, R.J.; Rick, D.L.; Freshour, N.L.; Saunders, J.H. Chlorpyrifos: Pharmacokinetics in human volunteers. Toxicol. Appl. Pharmacol. 1984, 73, 8-15.

20. Griffin, P.; Mason, H.; Heywood, K.; Cocker, J. Oral and dermal absorption of chlorpyrifos: A human volunteer study. Occup. Environ. Med. 1999, 56, 10-13.

21. Meuling, W.J.; Ravensberg, L.C.; Roza, L.; van Hemmen, J.J. Dermal absorption of chlorpyrifos in human volunteers. Int. Arch. Occup. Environ. Health 2005, 78, 44-50.

22. Garfitt, S.J.; Jones, K.; Mason, H.J.; Cocker, J. Exposure to the organophosphate diazinon: Data from a human volunteer study with oral and dermal doses. Toxicol. Lett. 2002, 134, 105-113.

23. ATSDR (Agency for Toxic Substances and Disease Registry). Toxicological Profile for Diazinon; US Department of Health and Human Services, Agency for Toxic Substances and Disease Registry: Atlanta, GA, USA, 2008. Available online: http://www.atsdr.cdc.gov/toxprofiles/tp86.pdf (accessed on 23 May 2011).

24. ATSDR (Agency for Toxic Substances and Disease Registry). Toxicological Profile for Pyrethrins and Pyrethroids; US Department of Health and Human Services, Agency for Toxic Substances and Disease Registry: Atlanta, GA, USA, 2003. Available online: http://www.atsdr.cdc.gov/toxprofiles/tp155.pdf (accessed on 23 May 2011).

25. NRC (National Research Council). Pesticides in the Diets of Infants and Children; National Academy Press: Washington, DC, USA, 1993; p. 386.

26. Bartelt, N.; Hubbell, J. Percutaneous Absorption of Topically Applied 14C-permethrin in Volunteers: Final Medical Report, 1987. Burroughs Wellcome Co. Cited in: National Research Council. Health Effects of Permethrin-Impregnated Army Battle-Dress Uniforms; National Academy Press: Washington, DC, USA, 1994.

27. Kissel, J.C. The mismeasure of dermal absorption. J. Expo. Sci. Environ. Epidemiol. 2011, 21, 302-309.

28. Leng, G.; Leng, A.; Kühn, K.H.; Lewalter, J.; Pauluhn, J. Human dose-excretion studies with the pyrethroid insecticide cyfluthrin: urinary metabolite profile following inhalation. Xenobiotica 1997, 27, 1273-1283.

29. Woollen, B.H.; Marsh, J.R.; Laird, W.J.; Lesser, J.E. The metabolism of cypermethrin in man: Differences in urinary metabolite profiles following oral and dermal administration. Xenobiotica 1992, 22, 983-991.

30. Fiserova-Bergerova, V. Application of toxicokinetic models to establish biological exposure indicators. Ann. Occup. Hyg. 1990, 34, 639-651. 
31. Ross, J.H.; Driver, J.H.; Cochran, R.C.; Thongsinthusak, T.; Krieger, R.I. Could pesticide toxicology studies be more relevant to occupational risk assessment? Ann. Occup. Hyg. 2001, 45, S5-S17.

32. Oberst, F.W.; Koon, W.S.; Christensen, M.K.; Crook, J.W.; Cresthull, P.; Freeman, G. Retention of inhaled sarin vapor and its effect on red blood cell cholinesterase activity in man. Clin. Pharmacol. Ther. 1968, 9, 421-427.

33. Timchalk, C.; Nolan, R.J.; Mendrala, A.L.; Dittenber, D.A.; Brzak, K.A.; Mattsson, J.L. A physiologically based pharmacokinetic and pharmacodynamic (PBPK/PD) model for the organophosphate insecticide chlorpyrifos in rats and humans. Toxicol. Sci. 2002, 66, 34-53.

34. Eadsforth, C.V.; Baldwin, M.K. Human dose-excretion studies with the pyrethroid insecticide, cypermethrin. Xenobiotica 1983, 13, 67-72.

35. Eadsforth, C.V.; Bragt, P.C.; van Sittert, N.J. Human dose-excretion studies with pyrethroid insecticides cypermethrin and alpha-cypermethrin: Relevance for biological monitoring. Xenobiotica 1988, 18, 603-614.

36. Feldmann, R.J.; Maibach, H.I. Percutaneous penetration of some pesticides and herbicides in man. Toxicol. Appl. Pharmacol. 1974, 28, 126-132.

37. Maibach, H.I.; Feldman, R.J.; Milby, T.H.; Serat, W.F. Regional variation in percutaneous penetration in man. Pesticides. Arch. Environ. Health 1971, 23, 208-211.

38. Wester, R.C.; Bucks, D.A.; Maibach, H.I. Human in vivo percutaneous absorption of pyrethrin and piperonyl butoxide. Food Chem. Toxicol. 1994, 32, 51-53.

39. Tulve, N.S.; Egeghy, P.P.; Fortmann, R.C.; Xue, J.; Evans, J.; Whitaker, D.A.; Croghan, C.W. Methodologies for estimating cumulative human exposures to current-use pyrethroid pesticides. J. Expo. Sci. Environ. Epidemiol. 2011, 21, 317-327.

40. Aprea, C.; Colosio, C.; Mammone, T.; Minoia, C.; Maroni, M. Biological monitoring of pesticide exposure: A review of analytical methods. J. Chromatogr. B 2002, 769, 191-219.

41. Demoute, J.P. A brief review of the environmental fate and metabolism of pyrethroids. Pestic. Sci. 1989, 27, 375-385.

42. Baker, S.E.; Olsson, A.O.; Barr, D.B. Isotope dilution high-performance liquid chromatographytandem mass spectrometry method for quantifying urinary metabolites of synthetic pyrethroid insecticides. Arch. Environ. Contam. Toxicol. 2004, 46, 281-288.

43. Kühn, K.; Wieseler, B.; Leng, G.; Idel, H. Toxicokinetics of pyrethroids in humans: Consequences for biological monitoring. Bull. Environ. Contam. Toxicol. 1999, 62, 101-108.

44. Krieger, R.I.; Bernard, C.E.; Dinoff, T.M.; Fell, L.; Osimitz, T.G.; Ross, J.H.; Ongsinthusak, T. Biomonitoring and whole body cotton dosimetry to estimate potential human dermal exposure to semivolatile chemicals. J. Expo. Anal. Environ. Epidemiol. 2000, 10, 50-57.

45. Gordon, S.M.; Callahan, P.J.; Nishioka, M.G.; Brinkman, M.C.; O’Rourke, M.K.; Lebowitz, M.D.; Mosschandreas, D.M. Residential environmental measurements in the National Human Exposure Assessment Survey (NHEXAS) pilot study in Arizona: Preliminary results for pesticides and VOCs. J. Expo. Anal. Environ. Epidemiol. 1999, 9, 456-470. 
46. Adgate, J.L.; Barr, D.B.; Clayton, C.A.; Eberly, L.E.; Freeman, N.C.G.; Lioy, P.J.; Needham, L.L.; Pellizzari, E.D.; Quackenboss, J.J.; Roy, A.; et al. Measurement of children's exposure to pesticides: Analysis of urinary metabolite levels in a probability-based sample. Environ. Health Perspect. 2001, 109, 583-590.

47. Morgan, M.K.; Sheldon, L.S.; Croghan, C.W.; Jones, P.A.; Robertson, G.L.; Chuang, J.C.; Wilson, N.K.; Lyu, C.W. Exposures of preschool children to chlorpyrifos and its degradation product 3,5,6-trichloro-2-pyridinol in their everyday environments. J. Expo. Anal. Environ. Epidemiol. 2005, 15, 297-309.

48. Morgan, M.K.; Sheldon, L.S.; Thomas, K.W.; Egeghy, P.P.; Croghan, C.W.; Jones, P.A.; Chuang, J.C.; Wilson, N.K. Adult and children's exposure to 2,4-D from multiple sources and pathways. J. Expo. Sci. Environ. Epidemiol. 2008, 18, 486-494.

49. Morgan, M.K.; Sheldon, L.S.; Jones, P.A.; Croghan, C.W.; Chuang, J.C.; Wilson, N.K. The reliability of using urinary biomarkers to estimate children's exposures to chlorpyrifos and diazinon. J. Expo. Sci. Environ. Epidemiol. 2011, 21, 280-290

50. Morgan, M.K.; Sheldon, L.S.; Croghan, C.W.; Jones, P.A.; Chuang, J.C.; Wilson, N.K. An observational study of 127 preschool children at their homes and daycare centers in Ohio: Environmental pathways to cis- and trans-permethrin exposure. Environ. Res. 2007, 104, 266-274.

51. Bradman, A.; Whitaker, D.; Quiros, L.; Castorina, R.; Henn, B.C.; Nishioka, M.; Morgan, J.; Barr, D.B.; Harnly, M.; Brisbin, J.A.; et al. Pesticides and their metabolites in the homes and urine of farmworker children living in the Salinas Valley, CA. J. Expo. Sci. Environ. Epidemiol. 2007, 17, 331-349.

52. Tulve, N.S.; Egeghy, P.P.; Fortmann, R.C.; Whitaker, D.A.; Nishioka, M.G.; Naeher, L.P.; Hilliard, A. Multimedia measurements and activity patterns in an observational pilot study of nine young children. J. Expo. Sci. Environ. Epidemiol. 2008, 18, 31-44.

53. Hore, P.; Robson, M.; Freeman, N.; Zhang, J.; Wartenberg, D.; Ozkaynak, H.; Tulve, N.; Sheldon, L.; Needham, L.; Barr, D.; Lioy, P.J. Chlorpyrifos accumulation patterns for child-accessible surfaces and objects and urinary metabolite excretion by children for 2 weeks after crack-and-crevice application. Environ. Health Perspect. 2005, 113, 211-219.

54. Morgan, M.K.; Stout, D.M.; Jones, P.A.; Barr, D.B. An observational study of the potential for human exposures to pet-borne diazinon residues following lawn applications. Environ. Res. 2008, 107, 336-342.

55. Hu, Y.A.; Akland, G.G.; Pellizzari, E.D.; Berry, M.R.; Melnyk, L.J. Use of pharmacokinetic modeling to design studies for pathway-specific exposure model evaluation. Environ. Health Perspect. 2004, 112, 1697-1703.

56. Baker, S.E.; Barr, D.B.; Driskell, W.J.; Beeson, M.D.; Needham, L.L. Quantification of selected pesticide metabolites in human urine using isotope dilution high-performance liquid chromatography/tandem mass spectrometry. J. Expo. Anal. Environ. Epidemiol. 2000, 10, 789-798.

57. Beeson, M.D.; Driskell, W.J.; Barr, D.B. Isotope dilution high-performance liquid chromatograpy/tandem mass spectrometry method for quantifying urinary metabolites of atrazine, malathion, and 2,4-dichlorophen-oxyacetic acid. Anal. Chem. 1999, 71, 3526-3530. 
58. Hill, R.H., Jr.; Head, S.L.; Baker, S.; Gregg, M.; Shealy, D.B.; Bailey, S.L.; Williams, C.C.; Sampson, E.J.; Needham, L.L. Pesticide residues in urine of adults living in the United States: Reference range concentrations. Environ. Res. 1995, 71, 99-108.

59. Morgan, M.K.; Sheldon, L.S.; Croghan, C.W.; Chuang, J.C.; Lordo, R.A.; Wilson, N.K.; Lyu, C.; Brinkman, M.; Morse, N.; Chou, Y.L.; et al. A Pilot Study of Children's Total Exposure to Persistent Pesticides and Other Persistent Organic Pollutants (CTEPP); U.S. Environmental Protection Agency: Washington, DC, USA, 2004; EPA/600/R-041/193.

60. CDC (Centers for Disease Control and Prevention)-National Center for Health Statistics (NCHS). National Health and Nutrition Examination Survey Data; U.S. Department of Health and Human Services, Centers for Disease Control and Prevention: Hyattsville, MD, USA, 2010. Available online: http://www.cdc.gov/nchs/nhanes.htm (accessed on 23 May 2011).

61. Fleiss, J. The Design and Analysis of Clinical Experiments; John Wiley \& Sons: New York, NY, USA, 1985.

62. Rappaport, S.M. Assessment of long-term exposures to toxic substances in air. Ann. Occup. Hyg. 1991, 35, 61-121.

63. Salita, M.; Macknin, M.; Medendorp, S.V.; Jahnke, D. First-morning urine specific gravity and enuresis in preschool children. Clin. Pediatr. (Phila) 1998, 37, 719-724.

64. Miller, R.C.; Brindle, E.; Holman, D.J.; Shofer, J.; Klein, N.A.; Soules, M.R.; O’Connor, K.A. Comparison of specific gravity and creatinine for normalizing urinary reproductive hormone concentrations. Clin. Chem. 2004, 50, 924-932.

65. US EPA. Child-specific Exposure Factors Handbook; National Center for Environmental Assessment: Washington, DC, USA, 2002; EPA/600/P-00/002B. Available from: National Information Service, Springfield, VA, USA; PB2003-101678 and http://www.epa.gov/ncea (accessed on 23 May 2011)

66. Arcury, T.A.; Grzywacz, J.G.; Barr, D.B.; Tapia, J.; Chen, H.; Quandt, S.A. Pesticide urinary metabolite levels of children in eastern North Carolina farmworker households. Environ. Health Perspect. 2007, 115, 1254-1260.

67. Kissel, J.C.; Curl, C.L.; Kedan, G.; Lu, C.; Griffith, W.; Barr, D.B.; Needham, L.L.; Fenske, R.A. Comparison of organophosphorus pesticide metabolite levels in single and multiple daily urine samples collected from preschool children in Washington State. J. Expo. Anal. Environ. Epidemiol. 2005, 15, 164-171.

68. Curwin, B.D.; Hein, M.J.; Sanderson, W.T.; Striley, C.; Heederik, D.; Kromhout, H.; Reynolds, S.J.; Alavanja, M.C. Urinary pesticide concentrations among children, mothers and fathers living in farm and non-farm households in Iowa. Ann. Occup. Hyg. 2007, 51, 53-65.

69. Naeher, L.P.; Tulve, N.S.; Egeghy, P.P.; Barr, D.B.; Adetona, O.; Fortmann, R.C.; Needham, L.L.; Bozeman, E.; Hilliard, A.; Sheldon, L.S. Organophosphorus and pyrethroid insecticide urinary metabolite concentrations in young children living in a southeastern United States city. Sci. Total Environ. 2010, 408, 1145-1153

70. Lu, C.; Toepel, K.; Irish, R.; Fenske, R.A.; Barr, D.B.; Bravo, R. Organic diets significantly lower children's dietary exposure to organophosphorus pesticides. Environ. Health Perspect. 2006, 114, 260-263. 
71. Becker, K.; Seiwert, M.; Angerer, J.; Kolossa-Gehring, M.; Hoppe, H.W.; Ball, M.; Schulz, C.; Thumulla, J.; Seifert, B. GerES IV pilot study: Assessment of the exposure of German children to organophosphorus and pyrethroid pesticides. Int. J. Hyg. Environ. Health 2006, 209, 221-233.

72. US EPA. Chlorpyrifos Revised Risk Assessment and Agreement with Registrants; U.S. Environmental Protection Agency, Office of Prevention, Pesticides, and Toxic Substances: Washington, DC, USA, 2000.

73. US EPA. Reregistration Eligibility Decision (RED) Diazinon; U.S. Environmental Protection Agency, Office of Prevention, Pesticides and Toxic Substances: Washington, DC, USA, 2006; EPA 738-R-04-006.

74. Whyatt, R.M.; Garfinkel, R.; Hoepner, L.A.; Andrews, H.; Holmes, D.; Williams, M.K.; Reyes, A.; Diaz, D.; Perera, F.P.; Camann, D.E.; Barr, D.B. A biomarker validation study of prenatal chlorpyrifos exposure within an inner-city cohort during pregnancy. Environ. Health Perspect. 2009, 117, 559-567.

75. Wilson, N.K.; Strauss, W.J.; Iroz-Elardo, N.; Chuang, J.C. Exposures of preschool children to chlorpyrifos, diazinon, pentachlorophenol, and 2,4-dichlorophenoxyacetic acid over 3 years from 2003 to 2005: A longitudinal model. J. Expo. Sci. Environ. Epidemiol. 2010, 20, 557-558.

76. Lu, C.; Barr, D.B.; Pearson, M.A.; Waller, L.A. Dietary intake and its contribution to longitudinal organophosphorus pesticide exposure in urban/suburban children. Environ. Health Perspect. 2008, 116, 537-542.

77. Miller, M.D.; Marty, M.A.; Arcus, A.; Brown, J.; Morry, D.; Sandy, M. Differences between children and adults: Implications for risk assessment at California EPA. Int. J. Toxicol. 2002, 21, 403-418.

78. Pang, Y.; MacIntosh, D.L.; Camann, D.E.; Ryan, P.B. Analysis of aggregate exposure to chlorpyrifos in the NHEXAS-Maryland investigation. Environ. Health Perspect. 2002, 110, 235-240.

79. Liu, K.; Stamler, J.; Dyer, A. Statistical methods to assess and minimize the role of intra-individual variability in obscuring the relationship between dietary lipids and serum cholesterol. J. Chronic. Dis. 1978, 31, 399-418.

80. Heederik, D.; Boleij, J.S.M.; Kromhout, H.; Smid, T. Use and analysis of exposure monitoring data in occupational epidemiology: An example of an epidemiological study in the Dutch animal food industry. Appl. Occup. Environ. Hyg. 1991, 5, 458-574.

81. Curwin, B.D.; Hein, M.J.; Sanderson, W.T.; Striley, C.; Heederik, D.; Kromhout, H.; Reynolds, S.J.; Alavanja, M.C. Urinary pesticide concentrations among children, mothers, and fathers living in farm and non-farm households in Iowa. Ann. Occup. Hyg. 2007, 51, 53-65.

81. Meeker, J.D.; Barr, D.B.; Ryan, L.; Herrick, R.F.; Bennett, D.H.; Bravo, R.; Hauser, R. Temporal variability of urinary levels of nonpersistent insecticides in adult men. J. Expo. Anal. Environ. Epidemiol. 2005, 15, 271-281.

82. Egeghy, P.P.; Quackenboss, J.J.; Catlin, S.; Ryan, P.B. Determinants of temporal variability in NHEXAS-Maryland environmental concentrations, exposures, and biomarkers. J. Expo. Anal. Environ. Epidemiol. 2005, 15, 388-397. 
84. Sobus, J.R.; Morgan, M.K.; Pleil, J.D.; Barr, D.B. Biomonitoring: Uses and Considerations for Assessing Nonoccupational Human Exposure to Pesticides. In Hayes' Handbook of Pesticide Toxicology, 3rd ed.; Krieger, R., Ed.; Elsevier: New York, NY, USA, 2010; pp. 1021-1036.

85. Clayton, C.; Pellizzari, E.; Whitmore, R.W.; Quackenboss, J.J. Distributions, associations, and partial aggregate exposure of pesticides and polynuclear aromatic hydrocarbons in the Minnesota Children's Pesticide Exposure Study (MNCPES). J. Expo. Anal. Environ. Epidemiol. 2003, 13, 100-111.

86. MacIntosh, D.L.; Kabiru, C.; Echols, S.L.; Ryan, P.B. Dietary exposure to chlorpyrifos and levels of 3,5,6-trichloro-2-pyridinol in urine. J. Expo. Anal. Environ. Epidemiol. 2001, 11, 279-285.

87. Xue, J.; Zartarian, V.; Moya, J.; Freeman, N.; Beamer, P.; Black, K.; Tulve, N.; Shalat, S. A meta-analysis of children's hand-to-mouth frequency data for estimating nondietary ingestion exposure. Risk Anal. 2007, 27, 411-420.

88. Lu, C.; Barr, D.B.; Pearson, M.A.; Walker, L.A.; Bravo, R. The attribution of urban and suburban children's exposure to synthetic pyrethroid insecticides: A longitudinal assessment. J. Expo. Sci. Environ. Epidemiol. 2009, 19, 69-78.

\section{Supplemental Materials}

Table S-1. Limits of detection $(\mathrm{ng} / \mathrm{mL})$ for each pesticide metabolite measured in the children's urine samples by study.

\begin{tabular}{|c|c|c|c|}
\hline Study & TCPy & IMP & 3-PBA \\
\hline NHEXAS-AZ & 1.0 & NA & NA \\
\hline MNCPES & 1.4 & NA & NA \\
\hline CTEPP-NC & 1.0 & NA & NA \\
\hline CTEPP-OH & 1.0 & NA & 0.2 \\
\hline JAX & 0.4 & 2.0 & 0.5 \\
\hline CPPAES & 1.0 & NA & NA \\
\hline PET & NA & 0.3 & NA \\
\hline DIYC & NA & 1.0 & NA \\
\hline
\end{tabular}

NA, Not Applicable. 
Figure S-1. Concentration versus time plots for urinary TCPy measurements among CTEPP-NC and CTEPP-OH participants reporting a recent pesticide application. Urines in panels $\mathrm{A}$ and $\mathrm{B}$ are without adjustment. Urines in panels $\mathrm{C}$ and $\mathrm{D}$ are adjusted by specific gravity. Note that not all voids within the 48 hour period were collected.
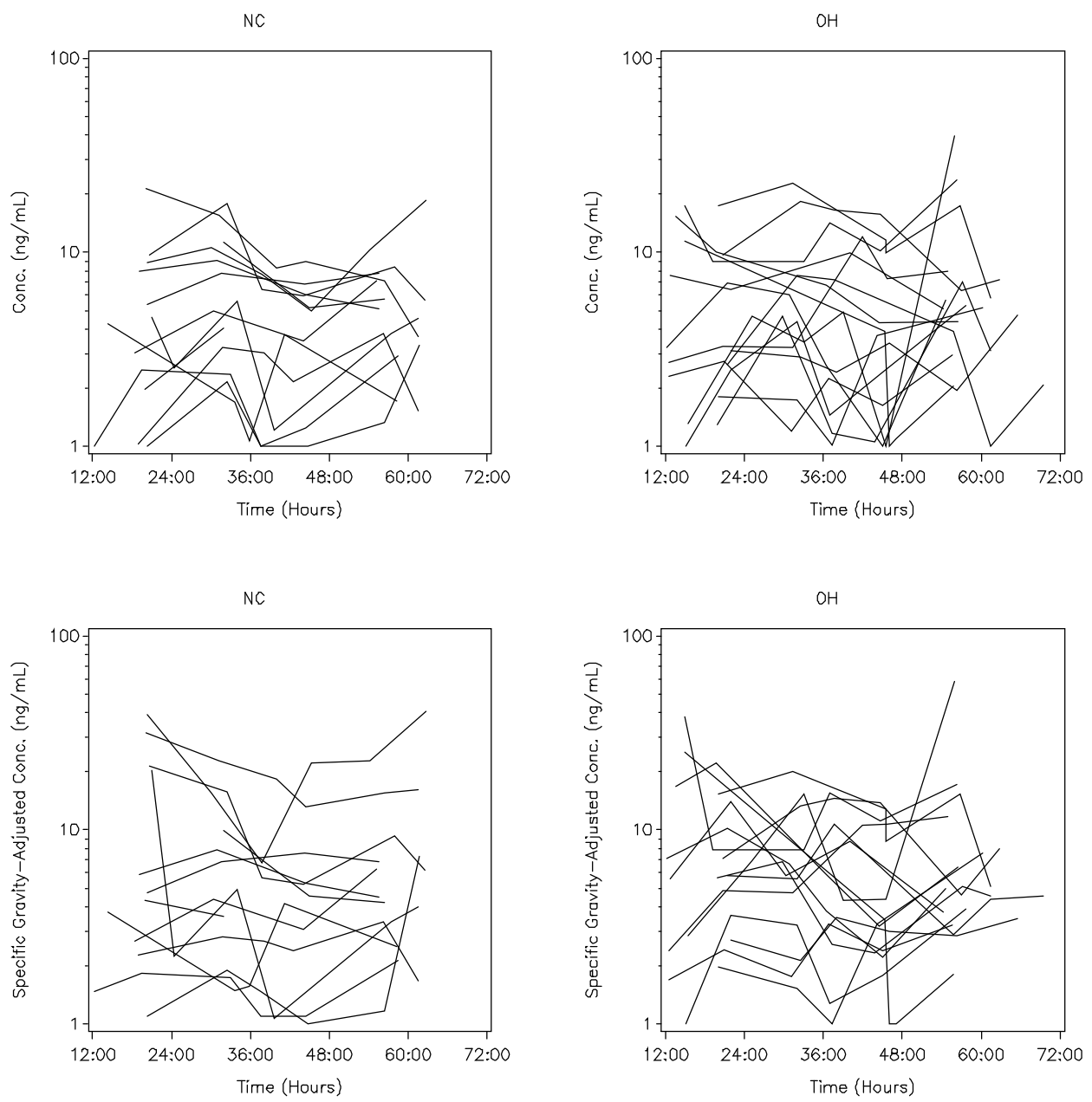

(C) 2011 by the authors; licensee MDPI, Basel, Switzerland. This article is an open access article distributed under the terms and conditions of the Creative Commons Attribution license (http://creativecommons.org/licenses/by/3.0/). 